\title{
POTENCIAL ANTIOXIDANTE E ANTIBACTERIANO CONTRA CORYNEBACTERIUM ULCERANS DO ÓLEO ESSENCIAL DE CANELA
}

\section{ANTIOXIDANT AND ANTIBACTERIAL POTENTIAL AGAINST CORYNEBACTERIUM ULCERANS OF THE ESSENTIAL CINNAMON OIL}

\author{
Pamela Ruth Santos Viana ${ }^{1,5}$; Denes Sousa Leite ${ }^{2,5}$; Ana Luíza de Mattos Guaraldi ${ }^{3}$, \\ Wellyson da Cunha Araújo Firmo ${ }^{4,6}$; Priscila Soares Sabbadini ${ }^{5,6}$
}

RESUMO: Corynebacterium ulcerans é um patógeno emergente em vários países, inclusive no Brasil, e está envolvido em diversos quadros clínicos, incluindo a difteria. O estudo da atividade antibacteriana de óleos essenciais (OEs), extraídos de plantas de interesse farmacológico, na busca de um antimicrobiano ideal tem sido bastante difundido. $\mathrm{O}$ objetivo desta pesquisa foi avaliar o potencial antioxidante e a atividade antibacteriana do OE obtido da canela. A partir das folhas da planta, coletadas no município de São Luís-MA, extraiu-se o óleo por hidrodestilação por arraste a vapor. Para avaliação da ação antioxidante do $\mathrm{OE}$ em diferentes concentrações, utilizou-se o método de quelação do íon ferroso. A fim de determinar a atividade antibacteriana, testes de difusão (disco e poço) em ágar e de determinação das concentrações inibitória mínima (CIM) por microdiluição e bactericida mínima $(\mathrm{CBM})$ foram realizados com seis isolados clínicos e uma amostra padrão de C. ulcerans. A capacidade do OE para quelar $50 \%$ do íon ferroso $\left(\mathrm{CE}_{50}\right)$ foi de $464,3 \pm 0,1726 \mu \mathrm{g} / \mathrm{mL}$. Nos testes de difusão em ágar, não foi observada a formação de halos de inibição bacteriana com as concentrações do OE utilizadas. Porém, foi possível determinar a CIM do OE para todas as amostras, sendo a menor de 3,90 $\mu \mathrm{g} / \mathrm{ml}$. Não se encontrou a CBM com as concentrações avaliadas. O OE de canela demonstrou ação antioxidante e antibacteriana contra $C$. ulcerans, sugerindo seu potencial para uso terapêutico.

PALAVRAS-CHAVE: corinebactérias; planta medicinal; antimicrobiano.

\footnotetext{
${ }^{1}$ Discente do curso de Biomedicina, $6^{\circ}$ período - Universidade CEUMA - UNICEUMA; voluntária de iniciação científica. E-mail: ruthvianna789@gmail.com

2Discente do curso de Biomedicina, 60 período - UNICEUMA; bolsista Fapema de iniciação científica. E-mail: denessousa27@gmail.com 3Bacharel em Ciências Biológicas Modalidade Médica pela Universidade do Estado do Rio de Janeiro - UERJ. Doutora em Ciências (Microbiologia) pela Universidade Federal do Rio de Janeiro - UFRJ. Laboratório de Difteria e Corinebactérias de Importância Clínica da UERJ. E-mail:aguaraldi@gmail.com

4Bacharel em Farmácia pela Faculdade de Imperatriz-FACIMP, Mestre em Saúde e Ambiente pela Universidade Federal do MaranhãoUFMA. Docente do curso de Biomedicina - UNICEUMA. E-mail: well_firmo@hotmail.com

${ }^{5}$ Bacharel em Ciências Biológicas - Modalidade Médica pela Universidade Federal do Estado do Rio de Janeiro, Docente do curso de Biomedicina - UNICEUMA. E-mail: prisabbadini@gmail.com

${ }^{6}$ Laboratório de Doenças Bacterianas Respiratórias e Sistêmicas - UNICEUMA.

Todos os autores são vinculados ao grupo de pesquisa do CNPq intitulado Estudos clínico-epidemiológicos, fenotípicos e moleculares de micro-organismos respiratórios e sistêmicos. Fonte de apoio à pesquisa - Fapema.
} 
ABSTRACT: Corynebacterium ulcerans is an emerging pathogen in umpteen countries, inclusive Brazil, and is involved in several clinical conditions, including diphtheria. The study of the antibacterial activity of essential oils (EOs) originating from plants of pharmacological interest in the search for an ideal antimicrobial has been quite widespread. The aim of this research was to evaluate the antioxidant potential and the antibacterial activity of EO obtained from cinnamon. The oil was extracted from the leaves of the plant collected in the municipality of São Luís-MA, Brazil by hydrodistillation using a Clevenger-type apparatus. The EO was assessed by ferrozine-ferrous ions assays to show antioxidant activity. The antimicrobial activities of the EO of cinnamon was evaluated against 7 strains of $C$. ulcerans. Aliquots of EO were placed on filter discs or cavities on the agar diffusios tests. The minimum inhibitory concentrations (MICs) and minimum bactericidal concentrations (MBCs) were tested. The investigation of antioxidant activity in vitro revealed a good antioxidant potential, as proved by the EC(50) value iron chelating activity. In the agar diffusion tests, EO from cinnamon can not inhibit the bacteria, but the EO demonstrated important antibacterial activities against $C$. ulcerans with detectable MIC values from $3.9 \mu \mathrm{g} / \mathrm{mL}$ to $125 \mu \mathrm{g}$ $/ \mathrm{mL}$. The MBC can not be determined with the concentrations evaluated. The results suggest that EO from cinnamon possess good antioxidant and antimicrobial properties, suggesting its potential for therapeutic use.

KEYWORDS: corynebacteria; medicinal plant; antimicrobial 


\section{Introdução}

Classicamente, Corynebacterium ulcerans tem sido descrito como agente causador de mastite em gado. Os primeiros casos de infecções em humanos foram normalmente associados ao consumo de leite não fervido/pasteurizado e derivados. Também há relatos de casos de trabalhadores rurais portadores assintomáticos do micro-organismo na nasofaringe (DIAS et al., 2011).

Apesar de pouco estudado, já foi documentado para C. ulcerans não só a habilidade para elaborar a fosfolipase D (PLD) (HODGSON et al., 1992), mas também potencial para produção de toxina Shiga-like, neuraminidase, endoglicosidase e pili (HACKER et al., 2016). Tais fatores de virulência contribuem para o desenvolvimento de diversos quadros clínicos, como infecção pulmonar, sinusite necrotizante e lesões dermonecróticas (HODGSON et al., 1992; MATTOSGUARALDI et al., 2008).

A preocupação com o potencial de C. ulcerans emergir como patógeno capaz de albergar o bacteriófago codificador de toxina diftérica (TD), com capacidade de causar a difteria zoonótica, já que o mesmo circula entre hospedeiros humanos e animais, não é recente (HODGSON et al., 1992; DIAS et al., 2011). O isolamento deste patógeno produtor de TD de quadros de difteria no continente europeu tem sido mais frequente que o de Corynebacterium diphtheriae, principal agente etiológico da difteria clássica (TAYLOR et al, 2010). No Brasil, foi descrito um caso de infecção fatal em humanos causada por C. ulcerans no Rio de Janeiro (MATTOS-GUARALDI et al., 2008). Entre 2014 e 2015, difteria por C. ulcerans foi relatada em Pernambuco (SILVA et al., 2017).

Pesquisadores de diferentes países buscam por uma droga ideal, ou seja, que apresente maior espectro de ação, menor toxicidade, menor custo e menor indício de resistência bacteriana, apesar da grande diversidade de antimicrobianos que agem sobre diversos micro-organismos patogênicos, incluindo as corinebactérias (PAZHANI, 2004).

Os óleos essenciais (OE) são parcialmente responsáveis pelas propriedades farmacêuticas descritas para as plantas medicinais (EDRIS, 2007). Dentre as atividades exercidas pelos OE, destacam-se as: antibacteriana, antiviral, antifúngica, antisséptica, fitoterápica e nutricional (BURT, 2004).

Considerando-se a magnitude dos conhecimentos adquiridos pela medicina popular e os crescentes relatos de resistência de C. ulcerans aos antimicrobianos, o presente trabalho tem como objetivo avaliar as atividades antioxidante e antimicrobiana do óleo essencial de canela. 


\section{MATERIAL E MÉTODOS}

\section{Coleta do material vegetal e obtenção do OE}

Foram coletadas folhas da espécie vegetal canela no município de São Luís -MA. O OE foi obtido utilizando equipamento tipo Clevenger e a metodologia padrão de arraste por vapor d'água. Após a extração, foi calculado o rendimento do OE (ADAMS, 2007).

\section{Avaliação da atividade antioxidante pela quelação do íon ferroso II}

A atividade antioxidante foi determinada usando $0,7 \mathrm{~mL}$ do $\mathrm{OE}$ nas concentrações de 1000 a $50 \mu \mathrm{g} / \mathrm{mL}$, diluído em $0,7 \mathrm{~mL}$ de água destilada e misturados com $0,175 \mathrm{~mL}$ de $\mathrm{FeCl}_{2}(0,5 \mathrm{mM})$. A absorbância foi medida a 550nm. Posteriormente, a reação foi iniciada pela adição de $0,175 \mathrm{~mL}$ de ferrozina $(0,5 \mathrm{mM})$. A mistura foi agitada vigorosamente e deixada à temperatura ambiente durante 20 min e a absorbância foi medida a 550nm. Como controle negativo, foi utilizada água destilada e ácido etilenodiamino tetra-acético (EDTA) a $0,5 \mathrm{mM}$ foi usado como controle positivo (BRUGNARI et al., 2016).

Para análise da atividade antioxidante, foi utilizado o teste de regressão não linear a partir do programa GraphPad Prism 6 ®, sendo esses expressos como média \pm desvio-padrão (GraphPad Software, San Diego, USA).

\section{Análise da atividade antibacteriana}

\section{Micro-organismos utilizados no estudo e cultivo}

Todas as amostras (Tabela 1) foram gentilmente cedidas pelo Laboratório de Difteria e Corinebactérias de Importância Clínica da Universidade do estado do Rio de Janeiro (LDCICUERJ) e estão estocadas em meio GC-glicerol $20 \%$ na bacterioteca do Laboratório de Doenças Bacterianas Respiratórias e Sistêmicas (LDBRS) da Universidade Ceuma. 
Para o estudo, os micro-organismos foram cultivados por $24-48 \mathrm{~h} / 37^{\circ} \mathrm{C}$ em meio Trypticase Soy Broth (TSB, Difco®), Trypticase Soy Agar (TSA, Difco $\left.{ }^{\circledR}\right)$ e/ou ágar sangue de carneiro e ágar chocolate telurito (SABBADINI et al., 2010).

Tabela 1. Amostras de Corynebacterium ulcerans utilizadas no estudo e suas características

\begin{tabular}{ccc}
\hline Amostras & Origem & Toxigenicidade \\
\hline CDC KC279 & Pneumonia/Humano/EUA & + \\
809 & Pneumonia/Humano/Brasil & + \\
2590 & Difteria/Humano/Brasil & + \\
2625 & Humano/Brasil & + \\
2630 & Humano/Brasil & + \\
2649 & Cão/Brasil & - \\
2652 & Cão/Brasil & - \\
\hline CDC, Centers for Disease Control and Prevention; EUA, Estados \\
Unidos da América; +, presença do gene que codifica a toxina \\
diftérica (TD); -, ausência do gene que codifica a TD. Fonte: Autores \\
(2018)
\end{tabular}

\section{Determinação da concentração inibitória mínima (CIM) pelos testes de difusão em discos e a partir de poços em meio sólido}

Discos de papel de filtro (6mm de diâmetro) estéreis foram embebidos com o OE e depositados sobre as placas de Petri contendo meio de cultura Ágar Müller-Hinton (AMH) inoculadas com as suspensões de micro-organismos $\left(1,5 \times 10^{8} \mathrm{UFC} \mathrm{mL}-1\right)$ preparados em salina. Nos testes utilizando poços confeccionadas no $\mathrm{AMH}$, os micro-organismos foram inoculados previamente à confecção dos poços (10 mm de diâmetro) nas placas, nos quais foram depositadas alíquotas do OE. Para ambos os experimentos, foram utilizadas concentrações de 1000 a $50 \mu \mathrm{g} / \mathrm{mL}$, diluídos em dimetilsulfóxido (DMSO) a $1 \%$. As placas foram incubadas a $37^{\circ} \mathrm{C} / 24 \mathrm{~h}$ e, transcorrido este período, foram medidos os diâmetros dos halos de inibição do crescimento, quando presentes. Como controle positivo, foram utilizadas penicilina e eritromicina; como controle negativo, DMSO $1 \%$ (FIRMO et al., 2014).

\section{Determinação da Concentração Inibitória Mínima (CIM) em meio líquido}

Esta metodologia foi realizada pela técnica de microdiluição em microplaca de 96 orifícios. Para isso, foram preparadas suspensões microbianas correspondentes a 0,5 da escala de McFarland (1,5 x $10^{8}$ UFC mL-1). A concentração de 4000 $\mu \mathrm{g} / \mathrm{mL}$ do OE foi diluída seriadamente na razão 1:2 para realização do teste. A revelação do ensaio foi pela adição de $30 \mu \mathrm{L}$ de resazurina 0,03\% em cada poço da microplaca. A CIM foi a menor concentração do OE onde não houve mudança de coloração do azul para róseo (SANTURIO et al., 2007) 


\section{RESULTADOS E DISCUSSÃO}

Na presente pesquisa, foi possível determinar estatisticamente que a concentração eficiente do OE de canela para quelar 50\% $\left(\mathrm{CE}_{50}\right)$ do íon ferroso foi de 464,3 $\pm 0,1726 \mu \mathrm{g} / \mathrm{mL}$ De acordo com a literatura (BRUGNARI et al., 2016), este valor de $\mathrm{CE}_{50}$ indica uma boa atividade antioxidante do OE.

Diversos estudos em relação ao potencial antioxidante da canela já foram demonstrados. Andrade et al. (2012), avaliando o OE e o extrato aquoso da casca de canela, demonstraram atividade antioxidante relevante desse vegetal.

Não se observou atividade antibacteriana em nenhuma das concentrações do OE de canela, no presente trabalho, pela técnicas de difusão em ágar a partir de discos e poços. Entretanto, Andrade et al., (2012) relataram que, em meio de cultura sólido (poço), foi possível visualizar a atividade antibacteriana do OE obtido da casca de canela para Staphylococcus aureus $(7,81 \mu \mathrm{g} / \mathrm{mL})$, Listeria monocytogenes $(7,81 \mu \mathrm{g} / \mathrm{mL})$, Escherichia coli $(15,62 \mu \mathrm{g} / \mathrm{mL})$, Pseudomonas aeruginosa $(7,81 \mu \mathrm{g} / \mathrm{mL})$ e Salmonella choleraisus $(15,62 \mu \mathrm{g} / \mathrm{mL})$. Nos ensaios em meio sólido (poço) relatados por Silveira et al. (2012) com o OE de folhas da canela foi possível determinar os valores das CIMs para S. aureus $(5 \mathrm{mg} / \mathrm{mL})$, L. monocytogenes $(2,5 \mathrm{mg} / \mathrm{mL})$, Bacillus cereus $(2,5 \mathrm{mg} / \mathrm{mL})$, Yersinia enterocolitica $(0,075 \mathrm{mg} / \mathrm{mL})$, E. coli $(5 \mathrm{mg} / \mathrm{mL})$ e Salmonella Typhimurium $(5 \mathrm{mg} / \mathrm{mL})$.

Apesar de não ter sido possível determinar a atividade antibacteriana do OE de canela em meio de cultura sólido, foram encontradas CIMs do OE para todas as amostras testadas quando se utilizou meio líquido (Tabela 2). Não foi possível determinar as CBMs com as concentrações analisadas.

Tabela 2. Concentrações inibitórias e bactericidas mínimas do óleo essencial de canela contra amostras de Corynebacterium ulcerans

\begin{tabular}{ccc}
\hline Amostras & CIM $(\boldsymbol{\mu g} / \mathbf{m L})$ & $\mathbf{C B M ~}(\boldsymbol{\mu g} / \mathbf{m L})$ \\
\hline CDC KC279 & 31,25 & - \\
809 & 7,81 & - \\
2590 & 125 & - \\
2625 & 31,25 & - \\
2630 & 3,90 & - \\
2649 & 125 & - \\
2652 & 7,81 & - \\
\hline
\end{tabular}

CIM, Concentração inibitória mínima; CBM, Concentração bactericida mínima; CDC, Centers for Disease Control and Prevention; -, resultado negativo com as concentrações avaliadas. Fonte: Autores (2018) 
Santurio et al., (2007), utilizando a microdiluição em caldo, também encontraram CIMs de 400 a $3200 \mu \mathrm{g} / \mathrm{mL}$ para o OE de canela frente a sorovares de Salmonella spp. A média das CBMs foi equivalente a $1979 \mu \mathrm{g} / \mathrm{mL}$. Santurio et al., (2011) encontraram médias de CIMs e CBMs para isolados de E. coli de 3098,5 $\mu \mathrm{g} / \mathrm{mL}$ e $4075,3 \mu \mathrm{g} / \mathrm{mL}$, respectivamente. Ressalta-se que, em comparação com os relatos na literatura para outras espécies bacterianas, os valores das CIMs do OE de canela determinados no presente estudo para C. ulcerans foram bem mais baixos.

\section{CONCLUSÃO}

O OE de canela demonstrou ação antioxidante significativa e ação antibacteriana contra todas as amostras de C. ulcerans avaliadas. Esses resultados sugerem seu potencial para uso terapêutico, sendo necessários mais estudos.

\section{REFERÊNCIAS}

ADAMS, RP. Identification of essential oils components by gas chromatography/mass spectroscopy. 4ª ed. Illinois, EUA: Allured Publishing Corporation, Carol Stream, 2007.

ANDRADE, M.A.; CARDOSO, M.G.; BATISTA, L.R.; MALLET, A.C.T.; MACHADO, S. M. F.; Óleos essenciais de Cymbopogon nardus, Cinnamomum zeylanicum e Zingiber officinale: composição, atividades antioxidante e antibacteriana. Revista Ciência Agronômica, v. 43, n. 2, p. 399-408, Abr-Jun, 2012.

BRUGNARI, T.; KATO, C.G.; CORREA, V.G.; FREITAS, E.N.; NOLLI, M.M.; SOUZA, C.G.M. Atividade antioxidante do extrato aquoso do cogumelo comestível Pleurotus ostreatus. Revista UNINGÁ. v. 25, p. 46-50, 2016.

BURT, S. Essential oils: their antibacterial properties and potential applications in foods-a review. Int J Food Microbiol, v.94, n.3, p. 223-53, 2004.

DIAS, A. A. S. O.; SANTOS, L. S.; SABBADINI, P. S.; SANTOS, C. S.; SILVA JUNIOR, F. C.; NAPOLEÃO, F.; NAGAO, P. E.; VILLAS-BÔAS, M. H. S.; HIRATA JUNIOR, R.; MATTOSGUARALDI, A. L. Difteria pelo Corynebacterium ulcerans: uma zoonose emergente no Brasil e no mundo. Rev. Saúde Pública. v.45, n.6, p.1176-91, 2011. 
EDRIS, A.E. Pharmaceutical and therapic potentials of essential oils and their individual volatile constituents: a review. Phytother Res, v.21, p.308-323, 2007.

FIRMO, W.C.A.; MIRANDA, M.V.; COUTINHO, G.S.L.; SILVEIRA, L.M.S.; OLEA, R.S.G. Estudo fitoquímico e avaliação da atividade antibacteriana de Lafoensia pacari (Lythraceae). Publ. UEPG Ci. Biol. Saúde, v.20, n.1, p.7-12, 2014.

HACKER, E.; ANTUNES, C.A.; MATTOS-GUARALDI, A. L.; BURKOVSKI, A.; TAUCH, A. Corynebacterium ulcerans, an emerging human pathogen. Future Microbiology, v. 11, n. 9, p. 1191-1208, 2016.

HODGSON AL, KRYWULT J, CORNER LA, ROTHEL JS, RADFORD AJ. Rational attenuation of Corynebacterium pseudotuberculosis: potential cheesy gland vaccine and live delivery vehicle. Infect Immun., v. 60, n.7, p. 2900-5, 1992.

MATTOS-GUARALDI AL, SAMPAIO JLM, SANTOS CS, PIMENTA FP, PEREIRA GA, PACHECO LGC, MIYOSHI A, AZEVEDO V, MOREIRA LO, GUTIERREZ FL, COSTA JLF, COSTA-FILHO R, DAMASCO PV, CAMELLO TCF, HIRATA JR R. First detection of Corynebacterium ulcerans producing a diphtheria-like toxin in a case of human with pulmonary infection in the Rio de Janeiro metropolitan area, Brazil. Mem Inst Oswaldo Cruz, v. 103, p. 396-400, 2008.

PAZHANI, G.P. et al. Clonal multidrug-resistant Shigella dysenteriae Type 1 strains associated with epidemic and sporadic dysenteries in Eastern India. Antimicrobial Agents Chemotherapy, v.48, n.2, p.681-4, 2004.

SABBADINI, P. S.; GENOVEZ, M. R. N.; SILVA, C. F.; ADELINO, T. L. N.; SANTOS, C. S.; PEREIRA, G. A.; NAGAO, P. E.; DIAS, A. A. D. S. O.; MATTOS-GUARALDI, A. L.; HIRATA JÚNIOR, R. Fibrinogen binds to nontoxigenic and toxigenic Corynebacterium diphtheriae strains. Mem. Inst. Oswaldo Cruz, v.105, n.5, p.706-711, 2010.

SANTURIO, D.F.; DA COSTA, M.M.; MABONI, G.; CAVALHEIRO, C.P.; DE SÁ, M.F.; POZZO, M.D.; ALVES, S.H.; FRIES, L.L.M. Atividade antimicrobiana de óleos essenciais de condimentos frente a amostras de Escherichia coli isoladas de aves e bovinos. Cienc. Rural, Santa Maria, v. 41, n. 6, p. 1051-1056, June 2011. 
SANTURIO, J.M.; SANTURIO, D.F.; POZZATTI, P.; MORAES, C.; FRANCHIN, P.R.; ALVES, S.H. Atividade antimicrobiana dos óleos essenciais de orégano, tomilho e canela frente a sorovares de Salmonella enterica de origem avícola. Ciência Rural. v. 37, p. 803-808, 2007.

SILVA, C.M.F.; LOURÊDO, L.S.; FIRMO, W.C.A.; SANTOS, L.S.; HIRATA JÚNIOR, R.; SABBADINI, P.S.; MATTOS-GUARALDI, A.L. Phenotypic and genotypic analysis of Corynebacterium ulcerans isolated from diphtheria outbreak in Pernambuco, Brazil. In: $1^{\circ}$ SIMPÓSIO INTERNACIONAL EM PATOGÊNESE MICROBIANA E DESENVOLVIMENTO DE DROGAS, 2017, São Luís, MA.

SILVEIRA, S.M.; JÚNIOR, A.C.; SCHEUERMANN, G.N.; SECCHI, F.L.; VIEIRA, C.R.W.; Chemical composition and antimicrobial activity of essential oils from selected herbs cultivated in the South of Brazil against food spoilage and foodborne pathogens. Cienc. Rural, Santa Maria, v. 42, n. 7, p. 1300-1306, July 2012.

TAYLOR, J.; SAVEEDRA-CAMPOS, M.; HARWOOD, D.; PRITCHARD, G. Toxigenic Corynebacterium ulcerans infection in a veterinary student in London, United Kingdon. Euro Surveill 15:1-3, 2010. 